\title{
Thermoelectric Properties of Amorphous Zr-Ni-Sn Thin Films Deposited by Magnetron Sputtering
}

\author{
YANG ZHOU, ${ }^{1}$ QING TAN,${ }^{1}$ JIE ZHU,${ }^{2}$ SIYANG LI, ${ }^{1}$ CHENJIN LIU, ${ }^{1}$ \\ YUXIONG LEI, ${ }^{1}$ and LIANGLIANG $\mathrm{LI}^{1,3}$ \\ 1.-State Key Laboratory of New Ceramics and Fine Processing, School of Materials Science and \\ Engineering, Tsinghua University, Beijing 100084, People's Republic of China. 2.-Institute of \\ Engineering Thermophysics, Chinese Academy of Sciences, Beijing 100190, People's Republic of \\ China. 3.-e-mail: liliangliang@mail.tsinghua.edu.cn
}

\begin{abstract}
n-Type Zr-Ni-Sn thermoelectric thin films with thickness of $60 \mathrm{~nm}$ to $400 \mathrm{~nm}$ were deposited by radiofrequency magnetron sputtering. The microstructure of the Zr-Ni-Sn thin films was examined by x-ray diffractometry and highresolution transmission electron microscopy, revealing an amorphous microstructure. The thermal conductivity of the amorphous films was measured by the ultrafast laser pump-probe thermoreflectance technique, revealing values of $1.4 \mathrm{~W} \mathrm{~m}^{-1} \mathrm{~K}^{-1}$ to $2.2 \mathrm{~W} \mathrm{~m}^{-1} \mathrm{~K}^{-1}$, smaller than that of bulk material because of the amorphous microstructure of the films. The effects of the sputtering power on the composition, Seebeck coefficient, and electrical conductivity of the films were investigated. The largest Seebeck coefficient and power factor were achieved at $393 \mathrm{~K}$, being $-112.0 \mu \mathrm{V} \mathrm{K}^{-1}$ and $2.66 \mathrm{~mW} \mathrm{~K}^{-2} \mathrm{~m}^{-1}$, respectively. The low thermal conductivity and high power factor indicate that amorphous $\mathrm{Zr}-\mathrm{Ni}-\mathrm{Sn}$ thin films could be a promising material for use in thermoelectric microdevices.
\end{abstract}

Key words: Zr-Ni-Sn, thin films, amorphous structure, magnetron sputtering, thermoelectric properties

\section{INTRODUCTION}

Thermoelectric materials and devices have attracted considerable interest due to their wide applications in energy harvesting, interstellar spacecraft, chip cooling, and wireless sensing. ${ }^{1,2}$ The dimensionless thermoelectric figure of merit $Z T$ of a material is defined as $Z T=S^{2} \sigma T / \kappa$, where $S$ is the Seebeck coefficient, $\sigma$ is the electrical conductivity, $T$ is the absolute temperature, and $\kappa$ is the thermal conductivity, including the carrier thermal conductivity $\kappa_{\mathrm{c}}$ and the lattice thermal conductivity $\kappa_{\mathrm{l}} . S^{2} \sigma$ is defined as the power factor. Recently, bulk ternary half-Heusler (HH) compounds such as MNiSn and $\mathrm{MCoSb}(\mathrm{M}=\mathrm{Ti}, \mathrm{Zr}$, and $\mathrm{Hf})$ have exhibited excellent transport properties and $Z T$ values close

(Received May 31, 2014; accepted December 23, 2014;

published online January 14, 2015) to those of state-of-the-art materials such as $\mathrm{PbTe}$ and $\mathrm{Bi}_{2} \mathrm{Te}_{3}$-based compounds. ${ }^{3-8}$ For MNiSn-based $\mathrm{HH}$ compounds, it has been found that a small amount of Sb doping can enhance $Z T$, with reliable values of 0.8 to $1.0{ }^{9,10}$ For MCoSb-based HH compounds, $Z T$ values have been improved to 0.51 owing to a remarkable reduction of the thermal conductivity. ${ }^{11,12}$

Besides bulk $\mathrm{HH}$ compounds, HH thin films have also been investigated because thin films have potential applications in portable devices, power electronics, wireless sensor networks, and other fields. ${ }^{13-16}$ There is an urgent need to develop thinfilm materials with high $Z T$ values. High-quality $\mathrm{NiMnSb}$ and NiYBi thin films have been deposited by radiofrequency (RF) magnetron sputtering or molecular-beam epitaxy. ${ }^{17-19}$ MNiSn-based $\mathrm{HH}$ thin films have also been synthesized by magnetron sputtering or electron beam deposition, exhibiting a largest Seebeck coefficient and power factor on the 
order of tens of $\mu \mathrm{V} \mathrm{K}^{-1}$ and on the order of $0.1 \mathrm{~mW} \mathrm{~K}^{-2} \mathrm{~m}^{-1}$, respectively. ${ }^{20-22}$

The reliable $Z T$ values of crystalline $\mathrm{HH}$ materials have been limited to around 1.0 so far, mainly due to the high thermal conductivity of $\mathrm{HH}$ compounds. ${ }^{23}$ Provided that the microstructure of a thermoelectric material is amorphous, the lattice thermal conductivity $\kappa_{1}$ of the material can be minimized and the total thermal conductivity $\kappa$ can be greatly reduced, which hence should enhance the $Z T$ value. For various kinds of thermoelectric materials such as $\mathrm{Zn}_{4} \mathrm{Sb}_{3}, \mathrm{Cu}-\mathrm{Ge}-\mathrm{Te}, \mathrm{Ge}$, and $\mathrm{Si}$, amorphous microstructure has indeed resulted in good thermoelectric properties. ${ }^{24-26}$ Nolas et al. suggested that amorphous $\mathrm{HH}$ alloys could be highefficiency thermoelectric materials. ${ }^{27}$

However, the thermoelectric properties of amorphous $\mathrm{HH}$ alloys have not been reported in the literature as far as we know. In this work, we synthesized $n$-type Zr-Ni-Sn thin films with an amorphous microstructure by $\mathrm{RF}$ magnetron sputtering and characterized the transport properties of the as-deposited films.

\section{EXPERIMENTAL PROCEDURES}

$n$-Type $\mathrm{Zr-Ni-Sn}$ films were deposited on $\mathrm{SiO}_{2}$ (300 $\mathrm{nm}$ thick)/Si substrates at room temperature (RT) by RF magnetron sputtering. A hot-pressed $\mathrm{Zr}_{34} \mathrm{Ni}_{31} \mathrm{Sn}_{35}$ target (diameter, 3 inches; 99.95 at.\%) was used. The base pressure in the sputtering chamber was below $1.5 \times 10^{-4} \mathrm{~Pa}$, the deposition pressure was $0.8 \mathrm{~Pa}$, and the Ar gas flow was $10 \mathrm{sccm}$. The sputtering power was $80 \mathrm{~W}, 100 \mathrm{~W}$, $120 \mathrm{~W}$ or $140 \mathrm{~W}$. Samples of three sizes $(4 \mathrm{~mm} \times 16 \mathrm{~mm}, 10 \mathrm{~mm} \times 10 \mathrm{~mm}$, and $4 \mathrm{~mm} \times$ $4 \mathrm{~mm}$ ) were simultaneously deposited. The $4 \mathrm{~mm} \times$ $16 \mathrm{~mm}$ samples were used for Seebeck measurements, whereas the $10 \mathrm{~mm} \times 10 \mathrm{~mm}$ and $4 \mathrm{~mm} \times$ $4 \mathrm{~mm}$ samples were used for Hall testing and other measurements. The film thickness was $60 \mathrm{~nm}$ to $400 \mathrm{~nm}$ for $1 \mathrm{~h}$ of sputtering.

The microstructure of the thin films was characterized by transmission electron microscopy (TEM, model JEM-2011, Japan Electron Optics Laboratory Co., LTD, Japan) and x-ray diffractometry (XRD) with a D/max-RB diffractometer (Rigaku, Japan) using $\mathrm{Cu} \mathrm{K}_{\alpha}$ radiation. The film composition was determined by inductively coupled plasma-atomic emission spectrometry (ICP-AES, VISTA-MPX, Varian Inc., USA). $\sigma$ was measured using the van der Pauw method on a four-probe station with a temperature-controlled stage. $S$ was measured by a customized setup with a good accuracy. ${ }^{28}$ The carrier concentration $n$ was measured using a Hall measurement setup (Resis-Hall test DC-8340, TOYO, Japan) with Ar gas protection. The mobility $\mu$ was obtained from the equation $\mu=\sigma / n e$, where $e$ is the charge of an electron. The $\kappa$ of the films at RT was measured by the ultrafast laser pump-probe thermoreflectance technique, whose details were mentioned in Refs. 29,30.

\section{RESULTS AND DISCUSSION}

The composition of the Zr-Ni-Sn films deposited with different sputtering powers is summarized in Table I, and the dependence of the concentration of each element on the sputtering power is plotted in Fig. 1. The concentration of Ni gradually decreased, that of $\mathrm{Zr}$ increased, and that of Sn was stable as the sputtering power was raised from $80 \mathrm{~W}$ to $140 \mathrm{~W}$. To study the microstructure of the films, XRD and high-resolution TEM (HRTEM) were carried out. Figure 2a shows the diffraction patterns of the as-deposited Zr-Ni-Sn films. No sharp peak was found, except for the diffraction peaks from the $\mathrm{Si}$ substrate. A broadened bump feature was observed, indicating an amorphous microstructure. Figure $2 \mathrm{~b}$ shows an HRTEM image of the sample deposited at sputtering power of $80 \mathrm{~W}$, which exhibited the best thermoelectric properties as shown in Table I. The HRTEM image clearly shows that the Zr-Ni-Sn film is not crystallized. The selected-area electron diffraction (SAED) image in Fig. $2 b$ presents two fuzzy rings that cannot be identified as $\mathrm{Zr}-\mathrm{Ni}$-Sn alloy or other binary alloys. Therefore, it can be concluded that the sputtered Zr-Ni-Sn thin film is amorphous, which may lead to low thermal conductivity. ${ }^{24}$

Figure 3a shows the Seebeck coefficients of the Zr-Ni-Sn thin films deposited with different powers as a function of temperature. The maximum error of the Seebeck coefficient measurement is within $\pm 8.4 \%$ according to our previous work. ${ }^{28}$ For the samples deposited at $80 \mathrm{~W}$ and $100 \mathrm{~W}$, the curves of $S$ show a concave-upward trend, whereas the variation of $S$ for the samples deposited at $120 \mathrm{~W}$ and $140 \mathrm{~W}$ exhibits a concave-downward trend. At RT, the sample deposited at $140 \mathrm{~W}$ has the largest $S$ value of $-83.5 \mu \mathrm{V} \mathrm{K}^{-1}$ among the four samples. The maximum $S$ over the whole temperature range occurs at $393 \mathrm{~K}$ for the sample deposited at $80 \mathrm{~W}$, being $-112.0 \mu \mathrm{V} \mathrm{K}^{-1}$. For HH alloys, $S, n$, and $\mu$ may be calculated by the following equations: $:^{31,32}$

$$
\begin{gathered}
|S|=\left|\frac{k_{\mathrm{B}}}{e}\left[\eta-\left(r+\frac{5}{2}\right)\right]\right|, \\
n=2\left(\frac{2 \pi m^{*} k_{\mathrm{B}} T}{h^{2}}\right)^{3 / 2} \exp (\eta), \\
\mu=\frac{4}{3 \pi^{1 / 2}}\left(r+\frac{5}{2}\right) \frac{e \tau_{0}\left(k_{\mathrm{B}} T\right)^{r}}{m^{*}}, \\
\eta=\left(E_{\mathrm{F}}-E_{\mathrm{C}}\right) /\left(k_{\mathrm{B}} T\right),
\end{gathered}
$$


Table I. Composition and transport properties (393 K) of Zr-Ni-Sn films deposited with different powers

\begin{tabular}{|c|c|c|c|c|c|c|}
\hline $\begin{array}{l}\text { Sputtering } \\
\text { Power (W) }\end{array}$ & $\begin{array}{c}\text { Zr/Ni/Sn Atomic } \\
\text { Ratio }\end{array}$ & $n\left(10^{21} \mathrm{~cm}^{-3}\right)$ & $\mu\left(\mathbf{c m}^{2} V^{-1} s^{-1}\right)$ & $\sigma\left(10^{3} \mathrm{~S} \mathrm{~cm}^{-1}\right)$ & $S\left(\mu \mathbf{V ~ K} \mathbf{K}^{-1}\right)$ & $S^{2} \sigma\left(\mathbf{m W ~ K ^ { - 2 }} \mathbf{m}^{-1}\right)$ \\
\hline 80 & $27.0 / 40.4 / 32.6$ & 0.27 & 49.1 & 2.12 & -112.0 & 2.66 \\
\hline 100 & 27.7/39.1/33.2 & 10.9 & 1.65 & 2.88 & -33.73 & 0.33 \\
\hline 120 & 29.5/38.2/32.3 & 2.91 & 7.33 & 3.41 & -42.10 & 0.60 \\
\hline 140 & $29.6 / 37.5 / 32.8$ & 1.02 & 20.4 & 3.33 & -31.17 & 0.32 \\
\hline
\end{tabular}

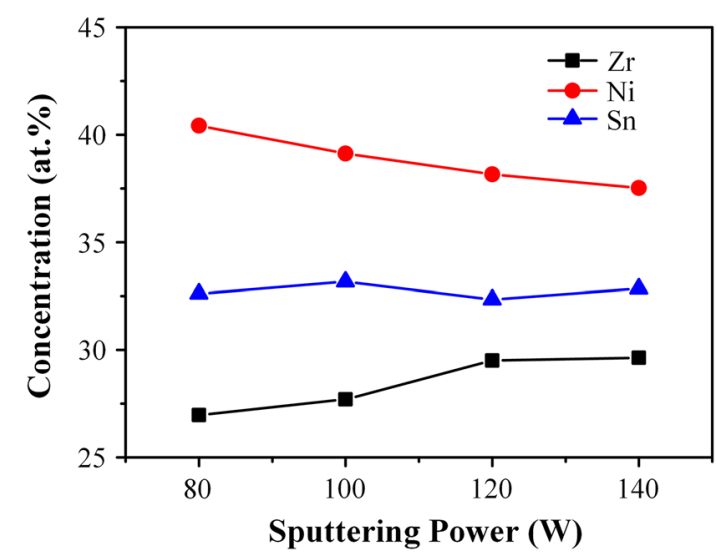

Fig. 1. Composition of Zr-Ni-Sn films as a function of sputtering power.

$$
\Gamma(m+1)=m \Gamma(m),
$$

where $h$ is Planck's constant, $m^{*}$ is the effective mass of the electron, $e$ is the electron charge, $T$ is the temperature, $k_{\mathrm{B}}$ is Boltzmann's constant, $\eta$ is the reduced chemical potential, $r$ is the scattering factor, and $E_{\mathrm{F}}$ and $E_{\mathrm{C}}$ are the Fermi energy and the energy of the conduction-band bottom. Therefore, $S$ is related with $n, \mu$, and $r$ according to Eqs. $1-3$. The composition of the $\mathrm{Zr}-\mathrm{Ni}-\mathrm{Sn}$ films changed as the sputtering power was varied, and thus all the $n, \mu$, and $r$ values may be different for these films. Generally, the absolute value of $S$ of $\mathrm{HH}$ alloys decreases as $n$ increases, ${ }^{32}$ which is also valid for the Zr-Ni-Sn films deposited at $80 \mathrm{~W}, 100 \mathrm{~W}$, and $120 \mathrm{~W}$. However, the sample deposited at $140 \mathrm{~W}$ showed the second smallest $n$ and smallest absolute value of $S$. This contradiction is possibly due to the variation of the scattering factor $r$. Maybe the scattering mechanism is different for the film deposited at $140 \mathrm{~W}$, because this particular sample has the maximum $\mathrm{Zr}$ content and minimum $\mathrm{Ni}$ content. More work on analysis of the carrier concentration and scattering mechanism in $\mathrm{Zr}-\mathrm{Ni}-\mathrm{Sn}$ films needs to be done in the future. Some $S$ data for $\mathrm{HH}$ alloys with similar carrier concentration from the literature are also summarized in Fig. 3a. The $S$ values of the samples in Refs. 32,33 (with $n$ of $0.23 \times 10^{21} \mathrm{~cm}^{-3}$ to $0.53 \times 10^{21} \mathrm{~cm}^{-3}$ ) are close to that of the film deposited at $80 \mathrm{~W}$. The $S$ value of the
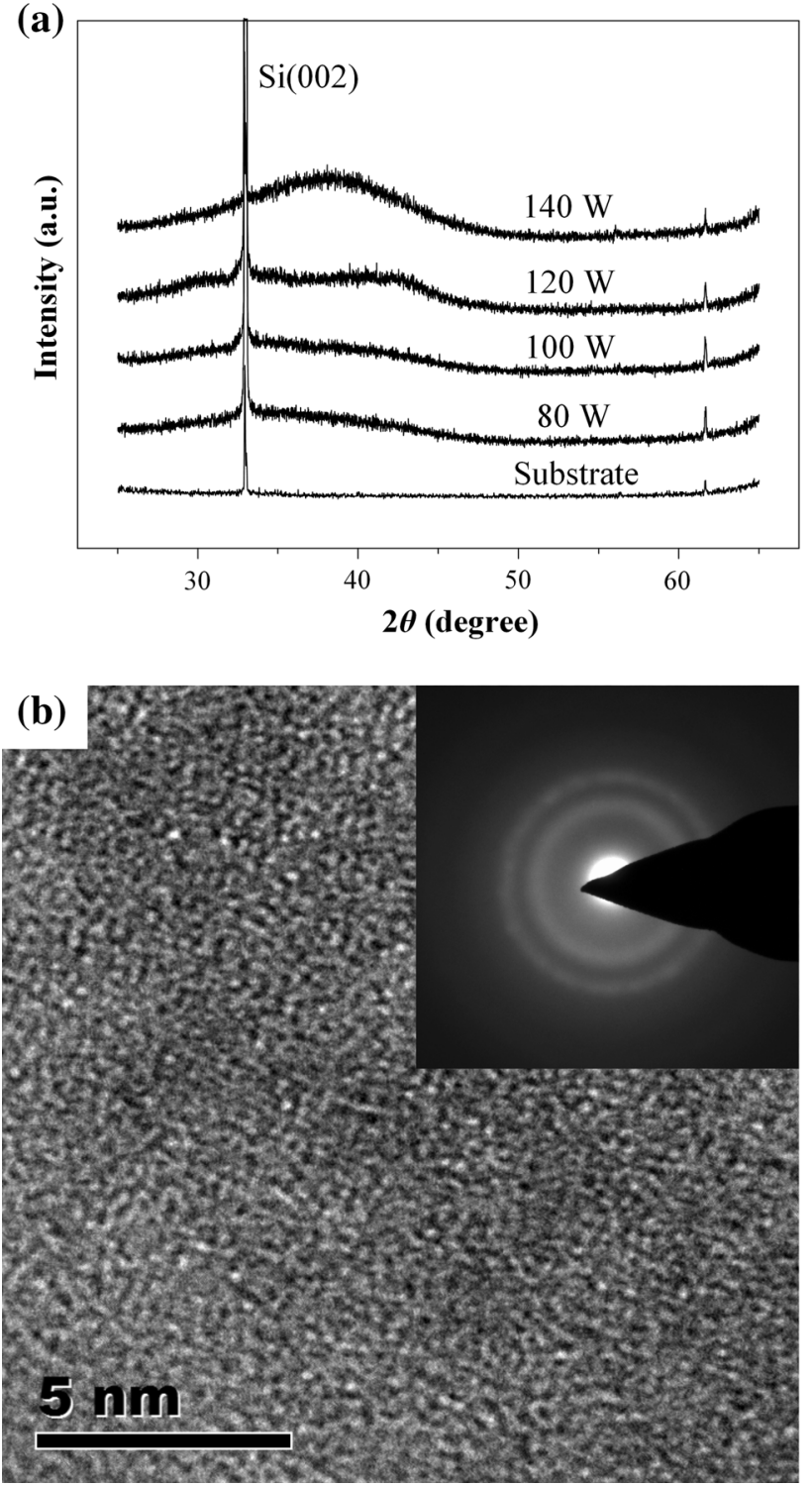

Fig. 2. (a) XRD patterns of Zr-Ni-Sn films sputtered with different powers, and (b) HRTEM and SAED images of $\mathrm{Zr}$-Ni-Sn film prepared with sputtering power of $80 \mathrm{~W}$.

sample with $n \approx 15 \times 10^{21} \mathrm{~cm}^{-3}$ in Ref. 33 is close to that of the film deposited at $100 \mathrm{~W}$.

Figure $3 \mathrm{~b}$ summarizes the temperature dependence of the electrical conductivity of the films. The error of the $\sigma$ measurement is estimated to be less 

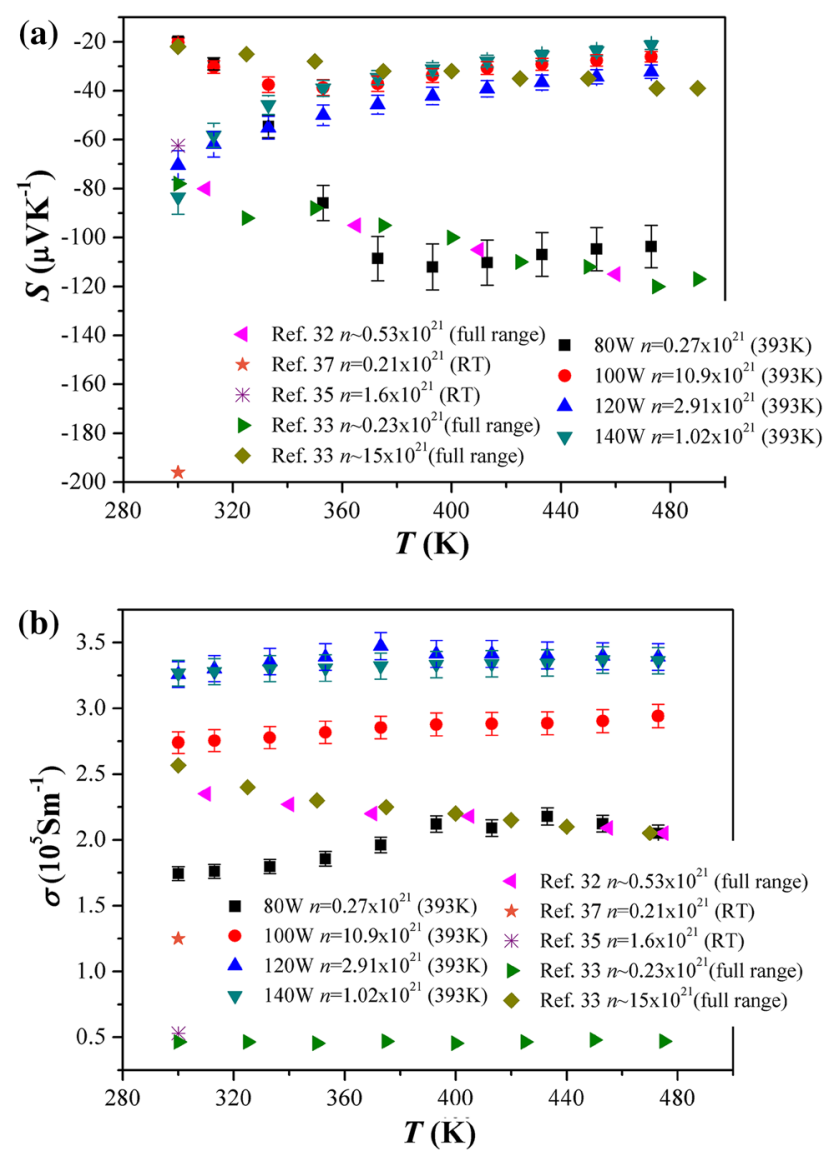

Fig. 3. (a) Seebeck coefficient and (b) electrical conductivity of Zr$\mathrm{Ni}$-Sn films deposited with different sputtering powers as a function of temperature.

than $\pm 3.0 \%$, taking into account the errors due to the geometry and the nonuniformity of samples as well as the error of the instrument (Agilent 34970A data acquisition unit) in the van der Pauw method. ${ }^{34}$ The $\sigma$ value of the Zr-Ni-Sn films does not vary significantly with temperature for each sample. In general, $\sigma$ increases with increase of the sputtering power, and the sample deposited at $80 \mathrm{~W}$ has the smallest $\sigma$. The electrical conductivity of our $\mathrm{Zr}-\mathrm{Ni}-\mathrm{Sn}$ films is larger than those of other M-Ni-Sn thin films. ${ }^{21,22}$ Again, the $\sigma$ value of the $\mathrm{Hf}_{0.65} \mathrm{Zr}_{0.35}$ $\mathrm{NiSn}_{0.98} \mathrm{Sb}_{0.02}$ sample in Ref. 32 is similar to that of the Zr-Ni-Sn film deposited at $80 \mathrm{~W}$. Taking into account both $\sigma$ and $S$, our Zr-Ni-Sn film deposited at $80 \mathrm{~W}$ has similar thermoelectric properties compared with the $\mathrm{Hf}_{0.65} \mathrm{Zr}_{0.35} \mathrm{NiSn}_{0.98} \mathrm{Sb}_{0.02}$ sample in Ref. 32. Although the $\sigma$ of the sample prepared at $80 \mathrm{~W}$ is the smallest among the four samples, its power factor $S^{2} \sigma$ becomes the largest when the temperature reaches $393 \mathrm{~K}$ owing to its maximum $S$, as shown in Fig. 4a. The largest value of $S^{2} \sigma$ is $2.66 \mathrm{~mW} \mathrm{~K}^{-2} \mathrm{~m}^{-1}$ at $393 \mathrm{~K}$, which is larger than those of other M-Ni-Sn films because both $S$ and $\sigma$ of this sample are enhanced. ${ }^{21,22}$ In addition, for the samples deposited at $120 \mathrm{~W}$ and $140 \mathrm{~W}$, the power

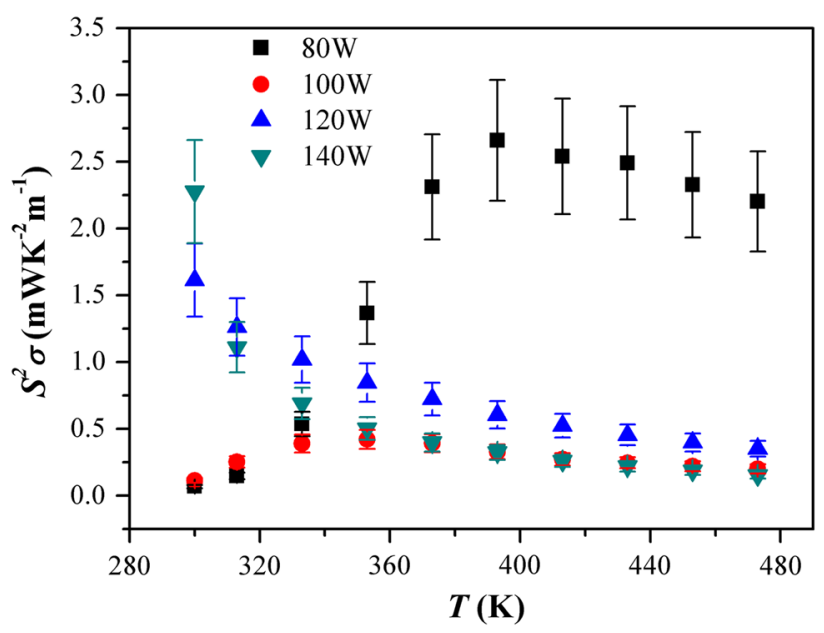

Fig. 4. Power factor of Zr-Ni-Sn films deposited with different sputtering powers as a function of temperature.

factors decrease with increasing $T$ due to the reduction of $S$.

The time-domain ultrafast laser pump-probe thermoreflectance technique was used to measure the thermal conductivity of the amorphous $\mathrm{Zr}-\mathrm{Ni}-\mathrm{Sn}$ thin films at RT. ${ }^{29,30}$ In this method, the measured ratio of the in-phase to the out-of-phase signal $\left(-V_{\text {in }} / V_{\text {out }}\right)$ as a function of the time interval $(\tau)$ between the pump beam and probe beam is fitted using a multilayered heat transfer model to obtain $\kappa .^{29,30}$ Figure 5 shows the time-domain thermal reflectance signals of the samples deposited at $80 \mathrm{~W}, 100 \mathrm{~W}, 120 \mathrm{~W}$, and $140 \mathrm{~W}$, whose $\kappa$ values were measured to be $1.40 \mathrm{~W} \mathrm{~m}^{-1} \mathrm{~K}^{-1}, 1.35 \mathrm{~W}$ $\mathrm{m}^{-1} \mathrm{~K}^{-1}, 2.20 \mathrm{~W} \mathrm{~m}^{-1} \mathrm{~K}^{-1}$, and $1.60 \mathrm{~W} \mathrm{~m}^{-1} \mathrm{~K}^{-1}$, respectively. The typical errors of the signals due to the uncertainties in the film thickness and the laser spot size are within $\pm 20 \%{ }^{30}$ Although only the $\kappa$ at RT was obtained due to the limitations of the equipment, these data provide useful information for $\mathrm{Zr}-\mathrm{Ni}$-Sn films since there is very little literature reporting the thermal conductivity of $\mathrm{HH}$ films. Table II lists typical values of thermal conductivity for M-Ni-Sn-based bulk materials and films. The thermal conductivity of $\mathrm{Zr}-\mathrm{Ni}$-Sn thin films was $1 \mathrm{~W} \mathrm{~m}^{-1} \mathrm{~K}^{-1}$ to $3 \mathrm{~W} \mathrm{~m}^{-1} \mathrm{~K}^{-1}, 35$ whereas that of $\mathrm{Zr}$ Ni-Sn bulk alloys was about $6 \mathrm{~W} \mathrm{~m}^{-1} \mathrm{~K}^{-1}$ to $17 \mathrm{~W} \mathrm{~m}^{-1} \mathrm{~K}^{-1}, 11,32,33,36-38$ which demonstrates that Zr-Ni-Sn films have lower thermal conductivity than their bulk counterparts. In addition, we prepared a bulk $\mathrm{Zr}_{30} \mathrm{Ni}_{40} \mathrm{Sn}_{30}$ sample by hot-pressing $\mathrm{Zn}, \mathrm{Ni}$, and Sn powders (using the same method as applied to make the sputtering target), measured its thermal diffusivity using the laser flash method (TC-9000, Ulvac-Riko, Japan), and calculated its RT thermal conductivity as $\kappa=\lambda C_{\mathrm{p}} \rho$, where $\lambda$ is the measured thermal diffusivity $\left(2.658 \times 10^{-2}\right.$ $\left.\mathrm{cm}^{2} \mathrm{~s}^{-1}\right), C_{\mathrm{p}}$ is the theoretical heat capacity $\left(0.302 \mathrm{~J} \mathrm{~g} \mathrm{~g}^{-1} \mathrm{~K}^{-1}\right)$, and $\rho$ is the measured density $\left(5.97 \mathrm{~g} \mathrm{~cm}^{-3}\right)$. The $\kappa$ of bulk $\mathrm{Zr}_{30} \mathrm{Ni}_{40} \mathrm{Sn}_{30}$ is 
Table II. Summary of thermal conductivity of M-Ni-Sn-based bulk materials and films at RT

\begin{tabular}{|c|c|c|c|}
\hline Material & $\kappa$ at $\mathrm{RT}\left(\mathrm{W} \mathbf{m}^{-1} \mathrm{~K}^{-1}\right)$ & Type & Reference \\
\hline $\mathrm{Zr}-\mathrm{Ni}-\mathrm{Sn}$ & $1.4-2.2$ & Film & This work \\
\hline TiNiSn & 2.8 & Film & 35 \\
\hline $\mathrm{Zr}_{0.5} \mathrm{Hf}_{0.5} \mathrm{NiSn}$ & 1.1 & Film & 35 \\
\hline $\mathrm{Zr}_{30} \mathrm{Ni}_{40} \mathrm{Sn}_{30}$ & 4.79 & Bulk & This work \\
\hline ZrNiSn & 11.4 & Bulk & 36 \\
\hline ZrNiSn & $5.9-17.2$ & Bulk & 37 \\
\hline $\mathrm{Zr}_{0.25} \mathrm{Hf}_{0.75} \mathrm{NiSn}$ & 5.37 & Bulk & 33 \\
\hline $\mathrm{Hf}_{0.65} \mathrm{Zr}_{0.35} \mathrm{Ni}_{1-z} \mathrm{Pt}_{z} \mathrm{Sn}_{0.98} \mathrm{Sb}_{0.02}$ & $4-7.5$ & Bulk & 32 \\
\hline $\mathrm{Zr}_{0.5} \mathrm{Hf}_{0.5} \mathrm{Ni}_{0.5} \mathrm{Pd}_{0.5} \mathrm{Sn}_{0.99} \mathrm{Sb}_{0.01}$ & 3.1 & Bulk & 36 \\
\hline$\left(\mathrm{Zr}_{0.5} \mathrm{Hf}_{0.5}\right)_{0.99} \mathrm{Ta}_{0.01} \mathrm{NiSn}$ & 5.4 & Bulk & 38 \\
\hline $\mathrm{Ti}_{0.5} \mathrm{Zr}_{0.25} \mathrm{Hf}_{0.25} \mathrm{Co}_{1-x} \mathrm{Ni}_{x} \mathrm{Sb}$ & $3.35-4.50$ & Bulk & 11 \\
\hline
\end{tabular}

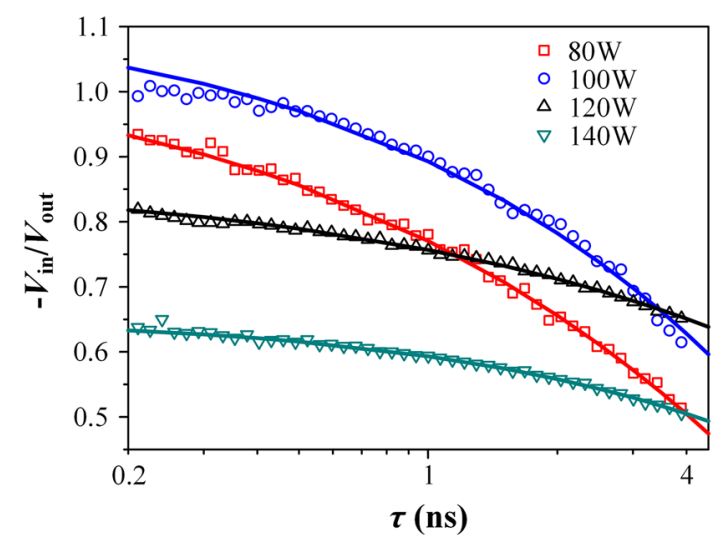

Fig. 5. Time-domain thermal reflectance signals of samples deposited at $80 \mathrm{~W}, 100 \mathrm{~W}, 120 \mathrm{~W}$, and $140 \mathrm{~W}$. The solid lines are fit curves to the measured data.

$4.79 \mathrm{~W} \mathrm{~m}^{-1} \mathrm{~K}^{-1}$, which confirms that the $\kappa$ of $\mathrm{Zr}-\mathrm{Ni}$ Sn material is closely related to the composition and synthesis method. Our thermal conductivity data obtained by the thermoreflectance technique are on the same order as other data reported for thin films, indicating that our measurement is reliable. From Table II, it can be seen that heavy elements such as $\mathrm{Hf}$, Ta, Pt, and $\mathrm{Sb}$ may be added into M-Ni-Sn alloys to increase the disorder in the material and to reduce the thermal conductivity. Since the $\mathrm{Zr}-\mathrm{Ni}-\mathrm{Sn}$ films have an amorphous structure, the disorder in the alloy is prominent and hence the thermal conductivity is low. The resulting amorphous structure is similar to that achieved by adding heavy elements.

\section{CONCLUSIONS}

Amorphous $n$-type Zr-Ni-Sn thin film was synthesized by RF magnetron sputtering. The thermal conductivity of the film was measured to be $1.4 \mathrm{~W} \mathrm{~m}^{-1} \mathrm{~K}^{-1}$ to $2.2 \mathrm{~W} \mathrm{~m}^{-1} \mathrm{~K}^{-1}$ by the ultrafast laser pump-probe thermoreflectance technique, which was attributed to the amorphous microstructure. A Seebeck coefficient of $-112.0 \mu \mathrm{V} \mathrm{K}^{-1}$ and a power factor of $2.66 \mathrm{~mW} \mathrm{~K}^{-2} \mathrm{~m}^{-1}$ were achieved at $393 \mathrm{~K}$ for the film deposited at sputtering power of $80 \mathrm{~W}$. The experimental data demonstrate that amorphous Zr-Ni-Sn thin film could be a promising material for use in thermoelectric microdevices because of its low thermal conductivity and high power factor.

\section{ACKNOWLEDGEMENTS}

This work was supported by the National Natural Science Foundation of China (Grant No. 51102149) and National Basic Research Program of China (Grant No. 2012CB933200). We thank Prof. Jing-Feng Li at Tsinghua University for help with laser flash measurements and Hall testing.

\section{REFERENCES}

1. F.J. DiSalvo, Science 285, 703 (1999).

2. L.E. Bell, Science 321, 1457 (2008).

3. J. Yang, H. Li, T. Wu, W. Zhang, L. Chen, and J. Yang, Adv. Funct. Mater. 18, 2880 (2008).

4. F. Casper, T. Graf, S. Chadov, B. Balke, and C. Felser, Semicond. Sci. Tech. 27, 063001 (2012).

5. B. Poudel, Q. Hao, Y. Ma, Y. Lan, A. Minnich, B. Yu, X. Yan, D. Wang, A. Muto, and D. Vashaee, Science 320, 634 (2008).

6. D. Li, L. Li, D.W. Liu, and J.-F. Li, Phys. Status Solidi-R 6, 268 (2012).

7. J. Jiang, L. Chen, Q. Yao, S. Bai, and Q. Wang, Mater. Chem. Phys. 92, 39 (2005).

8. W. Xie, J. He, H.J. Kang, X. Tang, S. Zhu, M. Laver, S. Wang, J.R.D. Copley, C.M. Brown, Q. Zhang, and T.M. Tritt, Nano Lett. 10, 3283 (2010).

9. C. Yu, T. Zhu, R. Shi, Y. Zhang, X. Zhao, and J. He, Acta Mater. 57, 2757 (2009).

10. S.R. Culp, S.J. Poon, N. Hickman, T.M. Tritt, and J. Blumm, Appl. Phys. Lett. 88, 042106 (2006).

11. W. Xie, Q. Jin, and X. Tang, J. Appl. Phys. 103, 043711 (2008).

12. M. Zhou, L. Chen, C. Feng, D. Wang, and J.-F. Li, J. Appl. Phys. 101, 113714 (2007).

13. D.-W. Liu, J.-F. Li, C. Chen, B.P. Zhang, and L. Li, J. Micromech. Microeng. 20, 125031 (2010).

14. I. Kim, Mater. Lett. 43, 221 (2000).

15. L.M. Goncalves, C. Couto, P. Alpuim, and J.H. Correia, J. Micromech. Microeng. 18, 064008 (2008).

16. I. Chowdhury, R. Prasher, K. Lofgreen, G. Chrysler, S. Narasimhan, R. Mahajan, D. Koester, R. Alley, and R. Venkatasubramanian, Nat. Nanotechnol. 4, 235 (2009). 
17. J.A. Caballero, Y.D. Park, A. Cabbibo, J.R. Childress, F. Petroff, and R. Morel, J. Appl. Phys. 81, 2740 (1997).

18. P. Bach, A.S. Bader, C. Rüster, C. Gould, C.R. Becker, G. Schmidt, L.W. Molenkamp, W. Weigand, C. Kumpf, E. Umbach, R. Urban, G. Woltersdorf, and B. Heinrich, Appl. Phys. Lett. 83, 521 (2003).

19. R. Shan, S. Ouardi, G.H. Fecher, L. Gao, A. Kellock, A. Gloskovskii, C.E. ViolBarbosa, E. Ikenaga, C. Felser, and S.S. Parkin, Appl. Phys. Lett. 101, 212102 (2012).

20. D.N. Compton, A.W.R. Leitch, J.H. Neethling and V.V. Kozyrkov, in Proceedings of 15th International Conference on Thermoelectrics, 491 (1996).

21. S.-H. Wang, H.-M. Cheng, R.-J. Wu, and W.-H. Chao, Thin Solid Films 518, 5901 (2010).

22. T. Jaeger, C. Mix, M. Schwall, X. Kozina, J. Barth, B. Balke, M. Finsterbusch, Y.U. Idzerda, C. Felser, and G. Jakob, Thin Solid Films 520, 1010 (2011).

23. Y. Kawaharada, K. Kurosaki, H. Muta, M. Uno, and S. Yamanaka, J. Alloys Compd. 384, 308 (2004).

24. Y. Wu, J. Nylén, C. Naseyowma, N. Newman, F.J. GarciaGarcia, and U. Häussermann, Chem. Mater. 21, 151 (2008).

25. A.P. Gonçalves, E.B. Lopes, O. Rouleau, and C. Godart, J. Mater. Chem. 20, 1516 (2010).

26. A.J. Lewis, Phys. Rev. B 13, 2565 (1976).

27. G.S. Nolas and H.J. Goldsmid, Phys. Status Solidi (a) 194, 271 (2002).
28. Y. Zhou, D. Yang, L. Li, F. Li, and J.-F. Li, Rev. Sci. Instrum. 85, 054904 (2014).

29. J. Liu, J. Zhu, M. Tian, X. Gu, A. Schmidt, and R. Yang, Rev. Sci. Instrum. 84, 034902 (2013).

30. J. Zhu, D. Tang, W. Wang, J. Liu, K.W. Holub, and R. Yang, J. Appl. Phys. 108, 094315 (2010).

31. H.J. Goldsmid, Introduction to Thermoelectricity (New York: Springer, 2009), pp. 23-34.

32. H. Xie, H. Wang, Y. Pei, C. Fu, X. Liu, G.J. Snyder, X. Zhao, and T. Zhu, Adv. Funct. Mater. 23, 5123 (2013).

33. J.P.A. Makongo, D.K. Misra, J.R. Salvador, N.J. Takas, G. Wang, M.R. Shabetai, A. Pant, P. Paudel, C. Uher, K.L. Stokes, and P.F.P. Poudeu, J. Solid State Chem. 184, 2948 (2011).

34. D.W. Koon, Rev. Sci. Instrum. 60, 271 (1989).

35. T. Jäger, Thermoelectric properties of TiNiSn and $\mathrm{Zr}_{0.5} \mathrm{Hf}_{0.5} \mathrm{NiSn}$ thin films and superlattices with reduced thermal conductivities. Dissertation, Johannes GutenbergUniversität Mainz, 2013.

36. Q. Shen, L. Chen, T. Goto, T. Hirai, J. Yang, G.P. Meisner, and C. Uher, Appl. Phys. Lett. 79, 4165 (2001).

37. C. Uher, J. Yang, S. Hu, D.T. Morelli, and G.P. Meisner, Phys. Rev. B 59, 8615 (1999).

38. H. Hohl, A.P. Ramirez, C. Goldmann, G. Ernst, B. Wölfing and E. Bucher, J. Phys. Condens. Matter 11, 1697 (1999). 